\title{
Авторски неологизми в сьвременната българска преса
}

\begin{abstract}
Zidarova Vanja, Avtorski neologizmi v syvremennata bylgarska presa (Author's Neologisms in the Contemporary Bulgarian Press). „Poznańskie Studia Slawistyczne” 8. Poznań 2015. Publishing House of the Poznań Society for the Advancement of the Arts and Sciences, pp. 391-400. ISSN 2084-3011.

Author's neologisms (so-called occasionalisms) are characteristic phenomena of the contemporary Bulgarian press. They are present in all components of the publishing text. Their purpose is to bring attractiveness in speech, voice the author's point of view in an expressive way, characterize the referent and attract the attention of the reader. Author's neologisms are manifestations of linguistic play and are based on the current literary word-formation rules. They are characterized by low frequency but high expressiveness. For this purpose, we use the creative possibilities of graphics, fonts, morphology, phonetics, semantic transposition.
\end{abstract}

KeYwords: press; publishing style; neologisms; expressiveness; derivation

Неологизмите са думи и значения, появили се или активизирали се в речника на езика в относително скорошно време, които пораждат усещане за новост у носителите на езика. Съществени за неологизмите признаци са: актуалност, новост, неутвърденост в колективната практика, все още ниска фреквентност. Понятието „неологизъм” е свързано с определен период от съществуването на думата - периода, в който тя все още не се е установила масово и трайно в езика и речта на хората. Причините за поява на нови думи и значения са главно номинативни и стилистични. Основна причина е развитието на обществената практика и общественото мислене, в резултат на което се появяват нови денотати. С оглед на нормалното протичане на комуникацията тези денотати трябва да бъдат назовани. Един от начините, по които може да се извърши номинацията, е чрез създаване на нова дума. Нови думи могат да възникват и поради стремежа да се обогатят 
номинативните възможности на речника. В този случай денотатът не е нов, а се създава или заема ново наименование, което по пътя на синонимията разширява изразните възможности на езика.

Неологизмите биват два основни вида - лексикални неологизми и авторски неологизми (оказионализми). Оказионализмите имат речев характер и не са част от езиковата система. Както показва терминът (occasio - случай), те възникват по повод на конкретна ситуация и в конкретен контекст. Обикновено оказионализмите не напускат рамките на този контекст и не се възпроизвеждат повторно. Те нямат номинативно, а по-скоро експресивно предназначение. Типът контекст, в който се реализират, е предимно от разговорната, публицистичната или художествената сфера. Създаването на авторски неологизми, независимо от сферата на поява, е свързано с по-високата степен на експресия и винаги е в противовес на книжовната лексикална норма. Авторите проявяват творческо отношение към езика, като се базират на словообразувателния му потенциал.

Една от сферите, в които авторската инициатива е особено разкрепостена, е публицистичната реч. За публицистиката е характерно съчетаването на информация с експресия, като по този начин се осъществява най-успешно присъщата на този стил функция. Експресивността позволява да се въздейства върху емоциите на адресата и да се постигне по-пряко и силно внушение на авторовите идеи. Медийният текст е вербален посредник между автора и читателя. Във функционално отношение този тип текст съчетава информативната и експресивната функция. Целта е да се създаде една относително реална картина на света и обществото, пречупена в по-малка или поголяма степен през визията на журналиста. За разлика от пресата преди 1989 г. днешната преса е усвоила много от разговорните речеви похвати. Субективното начало е силно изразено, както в интерпретацията на информацията, така и в избора на езиковите средства. Новата комуникативна стратегия на публицистичния стил, отхвърляйки старото, шаблонното, нормативното, модернизира публицистичния стил с различни експресивни средства. Публицистичният дискурс, съчетаващ стандарта и експресивността, днес определено разчита на силата на експресивността. Авторьт на публицистичния текст се стреми към максимално обновление на езиковите средства в две посоки 
- обновление на познатите експресивни средства и създаване на индивидуално авторски, оказионални експресивни средства (Цонева 2000). Този нов тип дискурс предоставя неограничени възможности за индивидуална интерпретация на лексикалните, морфологичните и синтактичните форми.

В лексикално отношение именно оказионализмите са основно средство за индивидуализация на изказа. Те са едно уникално явление, предназначено за специфични комуникативни цели, което се откроява на фона на преобладаващата книжовна нормативна лексика. С понятието „авторски неологизъмтук” означаваме всяка дума или словоформа, която е създадена за нуждите на конкретен текст и е резултат от преднамерена лексикална, семантична или графична проява на словотворчество, отличаваща се с ярка експресивност (Бонджолова 2009).

Във функционално-семантично отношение оказионализмите в пресата имат предимно сатиричен ефект, свързват се с негативна оценка, изграждат отрицателен образ. Най-често оценъчното отношение се проявява спрямо човек, засяга неговите физически и психически качества, неговите прояви и поведението му в обществото, значимостта му в социалната йерархия. Тази негативна оценка, от своя страна, дава информация за съвременната социална психология, за динамиката на обществените отношения, за авторската позиция по темата. Оказионалните словообразувания, които се създават с цел да се унизи адресатът, обикновено подчертават от позицията на говорещия активното неприемане на определен референт и се стремят да предизвикат съответната емоционална реакция у адресата. Характерна тенденция в новата преса е доминирането на негативното над позитивното. Иронизират се до степен на сарказъм официални институции и личности, като почти напълно се пренебрегва социалният респект.

В основата на оказионалното словообразуване стои езиковата игра, която цели да привлече вниманието на аудиторията. Тя може да се определи като специално нарушение на езиковите норми, на узуса, като специално творческо преобразуване на формата и значението на езиковите единици на различни равнища; тя е съзнателно „манипулиране" на езика, построено върху необичайното му използване с различни функции (Цонева 2000: 157). 
Играта с езика изисква обаче определена степен на лингвистична култура, за да се разберат и схванат правилно словесните трикове и да се постигне желаният ефект. Авторьт разчита на това, че читателят ще съумее да отгатне творческия замисъл, да оцени игровия момент и да го съпостави с езиковата норма.

Оказионализми се срещат в почти всички жанрове на публицистичния стил, както и в различни части на публицистичния текст. Ако в съответния жанр, към който принадлежи медийната изява, водеща роля има стандартът, вероятността за езикова игра и за създаване на оказионализми е по-ниска. Ако целта на съобщението е да предизвика определена реакция, при което доминираща е експресията, то проявите на езикова игра са по-чести. Това е причината, поради която в жанровете като памфлета, фейлетона, както и в страниците за лични мнения или мнение на редакцията, оказионализмите са по-чести. Оказионализми се наблюдават по-рядко в новинарски текстове, а по-често в коментарните, включително колоните на редакцията, на читателите, както и в рекламните текстове. Тъй като представляват един вид деформация, оказионализмите придават известна пародийност или шеговитост на текста. Оказионалната лексика се проявява и в други жанрове, в които водещо е личностното начало, като интервюта и репортажи.

В структурата на публицистичния текст оказионализми се употребяват без ограничения по отношение на позицията. Те се срещат както в заглавните комплекси, така и в основния текст, но доминиращо е присъствието им в заглавието. Силата на въздействието и ефективността на заглавието се планират предварително и целенасочено. То трябва да носи силен информационен заряд, но да бъде и интересно, атрактивно, да привлича вниманието и да оформя определени чувства. Изведени в заглавието, оказионализмите създават допълнителна връзка между него и основния текст. За минималния контекст на заглавието, което понякога съдържа само една оказионална дума, основният текст на материала е необходим, защото разкрива авторовата позиция, довела до словотворчеството. Това е причината в редица текстове новообразуваната дума да не се среща в основния текст, а само в заглавната позиция. Така заглавието е по-силен стимул за прочитане на статията. Например: „Добре дошли в Африканистан”, а след това 
в основния текст е пояснено: „Над градовете в северната част на Мали свободно се развяват черните знамена на «Ал Каида», а лидерите на Африканския клон на движението «Ал Каида в Ислямския Магреб» са се установили там. Неприятната аналогия с Афганистан от времето на талибаните изниква отново" (К, 19-25.01.2013). Заглавията с оказионализми притежават един важен общ признак - те са кратки, а колкото по-кратко е заглавието, толкова по-голям е семантичният капацитет (Бонджолова 2009: 59).

Оказионализмите, които се създават в основния текст и не са предварително презентирани в заглавния комплекс, също представляват интерес за изследователите. На тази закономерност се подчиняват оказионализми, които произтичат от последователността на разсъжденията и се преврьщат в ключови за разбиране на авторовата идея. Чрез тях авторът много по-силно въздейства на читателя, който се запознава със съдържанието на текста. Разпръскването на оказионализми в целия текст има организираща функция - по пътя на повторението на основата те акцентуват върху основната тема.

Широката употреба на оказионализми в българските медии се дължи на това, че те провокират естественото човешко любопитство, привличат с необичайната си форма, въздействат с многоплановостта си, както и с удоволствието, което декодирането им носи на реципиента. При всички положения ефектът от езиковата игра може да се счита за осъществен, само ако той се осъзнава от адресата, т.е. адресатът трябва да разбира, че нарушаването на нормата е целенасочено.

Важна специфика е, че оказионализмът не се създава поради липса на название, а като синоним на съществуваща лексема. Обикновено в основата на деривацията стои аналогията с реална дума от книжовната лексика или разпознаваемо правило за словообразуване: „охотелвам се” (ставам собственик на хотел), „гласовитка” (субстантивация на прилагателното име „гласовита”), „малеят” (глагол „намаляват”). Словесна алюзия с думата „папамобил” (автомобильт на Папата) се съдържа в заглавието „Не един, не три, а шест ЦЕЦОмобила кръстосвали България" (У, 20-26.04.2013, използвано е името на бившия вътрешен министър Цветан Цветанов).

Любим похват е „заиграването” със собствени имена. Чрез композиция, афиксация, контаминация или апелативизация се получават 
оказионални деривати с ярко изразена експресивност. Създава се и добра възможност за характеризация на референта с оглед на характерни негови признаци, като оценката е в повечето случаи негативна. Например: „Ако аз съм учителка, която трябва да пусне Криско в по-горен естетически клас, бих го оставил да повтаря. Освен това вместо оценка бих написал в дневника Кризис Ко” (Ш, 2012, бр. 14), „От днес Антония Петрова заслужава ново име и то е Анти-Тония” (Ш, 07-13.03.2012). Името на премиера на Унгария Виктор Орбан е използвано за образуване на фиктивен топоним: „Орбанистан” (К, 07-13.01.2012). От същото име е получен и друг оказионализъм - „викататура” (К, бр. 26, 2005). Името на Волен Сидеров, лидер на партията „Атака”, е особено често използвано за всякакви номинативни игри, в които се визират характерни за поведението на този политик качества - Волен Лидеров, Болен Лидеров, Хайл Сидеров, Болен Сидеров (К, бр. 26, 2005). Неологизъм, получен от контаминацията на две собствени имена - лидера на партията РЗС Яне Янев и политика Веселин Марешки - намираме в заглавието „Проектът Ярешки" (К, 9-15.03.2013), като дериватьт допълнително се асоциира и с нарицателното име ,яре”. Поради високата си производност едно и също собствено или фамилно име може да стане основа на няколко оказионализма. Например срещаме няколко варианта на игра с имената на канцлера на Германия Ангела Меркел и на бившия президент на Франция Никола Саркози. В пресата това роди неологизма „Меркози”, обозначаващ водещия дует на Европа (К, 14-20.01.2012). Чрез оказионално словообразуване е създаден и втори вариант на фамилното име Меркел, но този път с фамилията на настоящия президент на Франция Франсоа Оланд: „Меркози или Мерколанд?... Тя вече направи своя избор и засвидетелства пълната си и безусловна подкрепа за френския президент Никола Саркози, който след по-малко от сто дни ще се изправи в битка за втори мандат срещу социалиста Франсоа Оланд” (К, 18-24.02.2012). От собствени имена често се създават апелативи с нарицателен характер: „Чавизмът: а сега накъде” (К, 9-15.03.2013 визира се името на бившия президент на Венецуела Уго Чавес). Прозрачен намек за по-пълната фигура на една телевизионна водеща откриваме в примера: „Светската хроникьорка Джуджанка да се нарича Джоланка по куп причини, най-вече заради обилното 
слюнкоотделяне, което предизвиква сред гладуващите зрители, любители на свинското" (джолан - свински крак; У, 21-27.04.2012).

При авторското словообразуване много често се прибягва до типичните за книжовния език морфеми и похвати (афиксация, композиция), но в необичайна комбинация. На интересна контаминация между „шок” и „шопинг” е заложено в следния пример: „И продължи с шокинга: Имам си профил в еротичен сайт" (Ш, 21-27.03.2012). Също на контаминация е заложено в оказионализма кметьл от „кмет” и „метъл” („Кметъла Цонко Цонев положи началото на рок алеята в парка на Каварна", кметьт на Каварна Цонко Цонев е известен със страстта си към метъл музиката (СГ, 23.02.2013). Именно неочакваното съчетание на морфеми и основи поражда експресивността на такива деривати. Разчита се на способността на читателя да разпознае похвата, да направи аналогия с подобни книжовни форми и да долови игровия момент. Например: Да създадат нещо като тандемократия, включително и медийна (Ш, 29.02-06.03.2012), Това не е единствената атакувана от гедебопаджиите фирма (Ш, 22-28.02.2012, ГДБОП - Генерална дирекция за борба с организираната престъпност), Рубладжии, доларджии и летящи килимчета (У, 21-27.04.2012,), Една част от червените куфарчовци се издъниха като бизнесмени (Ш, 713.03.2012). Не само че не го правят, ами са готови и да се снимат с всеки случайник (У, 21-27.01.2012).

Често срещан похват е и разширяването на парадигмата чрез образуване на морфологични категории или морфологични форми, каквито дадената дума не притежава в системата на езика. Тук могат да се отнесат образуването на сьществителни с умалително значение, каквито няма в езика, образуване на несъществуващи родови форми, членуване на собствени имена и т.н. Например: Не искам СДС да е безлична опозицийка (Цонева 2000: 39) Звезди и звездички се надпреварваха за медийно внимание и малко пиарец с изтьркани лесбоизпьлнения (Ш, 29.02-6.03.2012). Образно казано, тези гейове и гейки не са се наживели поради липсата на достатъчно свобода, толерантност и хомосредища у нас и самата им природа се бунтува срещу закрепостяването по двойки (Ш, 22-28.02.2012).

С по-висока степен на сложност и с изискване за повече оригиналност са графичните оказионализми. За тяхното образуване се 
използват широките възможности, които дава графиката. Поради поособената си структура те довеждат до сложни и многопластови асоциации при възприемане на текстовете, в които функционират. За създаването им и за дешифрирането им е необходима по-висока степен на езикова култура и креативност. Към графичните средства се числят различните случаи на графично отделяне (с друг цвят, с курсив, с по-едър шрифт) на думи и части от думи в публицистичния текст. За разлика от другите видове оказионализми графичните невинаги са свързани със словотворчество. Често се мотивират от нетрадиционен словообразувателен анализ: обикновено в структурата на лексикална единица се открива конструктивен елемент, който не е сред мотивиращите думи или форманти, а е резултат на случайно съвпадение или сходство, на омонимно или паронимно звучене. По този начин се разчита на оригинално преразлагане, на изтькване на различна от реалната вътрешна форма. Различните модели за създаването на графични оказионализми обикновено възникват за нуждите на рекламата, която е по-свободна в избора на изобразителни средства, и после преминават в публицистиката. Писането на главни букви в средисловие не е присъщо за българския език. В такива оказионализми главната буква е знак за въвеждане на нов компонент в състава на сложното наименование. Затова използването на главни букви в думата за изтъкване на части от нея засилва игровото внушение.

В много случаи главните букви се използват, за да се подчертае едната основа при оказионализми, създадени най-често чрез субституция, контаминиране или междусловно налагане: „А аз не искам България да бъде управлявана от БОЙ-КОрпорейшън" (СГ 7.02.2003, използвано е името на бившия премиер на България Бойко Борисов) или „Да не изЧЕЗнеш за 24 часа” (К, 23.02-01.03.2013), където в глагола е вплетена абревиатурата ЧЕЗ, дружество за електроразпределение в Западна България.

Много често графичните оказионализми се проявяват в заглавието на публикация, тъй като това е свързана с неговата рекламна функция. Така например публикация за коментарите на футболни срещи в радиото и телевизията е озаглавена „ГОООЛеми глупости, драги зрители!” (Бонджолова 2004: 230). Изтъкването на елемент в дадена дума обикновено се дължи на необходимостта да се подчертае някаква 
особена зависимост между реалиите, които са свързани в обиграваните думи. С помощта на графиката читателят по-лесно може да открие асоциацията, която авторът му подсказва. Обикновено в контекста присъстват данни, които насочват към отделните компоненти. За графика от този тип В. Бонджолова дава пример с материал, разглеждащ включването на Васил Илиев-Лучано в листите на НДСВ, което е наричано „царска партия”: „Появи се и предложение пицария „Лучано" да бъде преименувана на пиЦАРия" (Бонджолова 2004: 230). Графично изтъкнатият елемент може да бъде лексикална единица, собствено име или абревиатура: „Ние не живеем в република България, а в КРАЛство България! Всичко се краде” (Ш, 14-20.03.2012), както и „Певецът, който има вид на РАФИнирано момче, обслужва нечии стилистични намерения, без да му подхождат нито на възрастта, нито на бликащата отвътре свежест, нито на ръста" (Ш, 4-10.01.2012). В последния пример става дума за младия певец Рафи Бохосян, победител в първото издание на „Х Фактор” през 2011 година.

Към графичните оказионализми можем да отнесем и тези, при които наред с кирилицата се използват графеми от латиницата. Вниманието на читателя е провокирано от съчетаването на домашни и чужди графеми или пък от съчетаването на домашна дума (изписана на кирилица) и чужда дума, най-често английска (изписана на латиница): frontwoman-ка, fashion бог, Нокътville (Бонджолова 2004: 233). Други подобни примери: „Нейният разкошен изкуствен бюст в скоро време може наистина да R.I.P.-не” (Ш, 10-16.01.2012). „Harlem-ският римейк на «Вчера»" (К, 9-15.03.2013)

Разновидност на графичните неологизми е използването на скоби не с пунктуационна, а със семантико-словообразувателна функция. Четенето на текста със и без поставеното в скоби представя съдържанието двояко. Поради тази причина много често се прилага в заглавия за създаване на занимателен ефект: „Лука(но)ви травестити” (У, 26.05-1.06.2012); „С (раз)вързани ръце” (Бонджолова 2009).

Авторските неологизми (оказионализми) са своеобразен синтез между индивидуалното възприемане на света и езика, те са проява на лексикална инициативност и разкриват пишещия като оригинална езикова личност. За целта обаче трябва да се познават отлично книжовните норми, книжовното словообразуване, както и възможностите за езикова 
игра, без да се нарушава номинативно-комуникативния характер на текста. Интересът на журналистите към използването на авторски неологизми е породен от ред причини. На първо място трябва да се постави очакваният ефект, който трябва да произведат върху реципиента заради своята уникалност. Използването на оказионализми може да се обясни и с това, че новите словообразувания разрушават стереотипите на възприятие, дават възможност по-пълно и точно да се изразят собствени мисли и чувства, да се даде оценка на ставащото, да се усили емоционално-експресивната изразителност на речта, да се икономисат езикови средства (Бонджолова 2005). Не бива да се подценява и елементът на изненада. Но все пак на първо място ефектът, който се търси със създаването на авторска дума, е експресивност и оценъчност. Неслучайно поголямата част от примерите тук са ексцерпирани от таблоидната преса - вестник „Шоу”, вестник „Уикенд”. В този тип преса езиковата свобода е по-голяма. В информационната преса неологизмите са сравнително по-малко на брой и с по-умерена оценъчност.

Индекс на ексцерпираните източници

К - Вестник „Капитал”, 2005, 2012, 2013

СГ - Вестник „Сега”, 2003, 2013

У - Вестник „Уикенд”, 2012, 2013

Ш - Вестник „Шоу”, 2012

\section{Литература}

Бонджолова В., 2004, Феминативите - между неологичното и оказионалното, „Научни трудове на ВТУ” кн. 2, с. 59-70.

Бонджолова В., 2005, За оказионалното словообразуване в българския език, в: К. Цанков, Български проучвания, т. 10: Актуални проблеми на българистиката и славистиката, Велико Търново, с. 141-154.

Бонджолова В., 2009, (Не)съществуващите думи: оказионализмите в медийния текст, Велико Търново.

Ницолова Р., 1999, Основни тенденции в развитието на българския печат след 1989, София.

Радева В., 2007, В света на думите. Структура и значение на производните думи, София.

Цонева Л., 2000, Езиковата игра в съвременната публииистика, Велико Търново. 